\title{
On the Tree-Cutting Problem under INTEREST RATE AND FOREST VALUE UNCERTAINTY
}

\author{
LUIS H. R. ALVAREZ \\ ERKKI KOSKELA
}

CESIFO WORKING PAPER NO. 870 CATEGORY 8: RESOURCES AND ENVIRONMENT FEBRUARY 2003 


\title{
ON THE TREe-CutTing PROBLEM UNDER INTEREST RATE AND FOREST VALUE UNCERTAINTY
}

\begin{abstract}
The current literature on optimal forest rotation makes the unrealistic assumption of constant interest rate though harvesting decisions of forest stands are typically subject to long time horizons. We apply the Wicksellian single rotation framework to cover the unexplored case of variable and stochastic interest rate. By modelling the stochastic interest rate according to the Cox-Ingersoll-Ross model and the forest value as a geometric Brownian motion we provide an explicit solution for the Wicksellian single rotation problem and show that increased interest rate volatility increases the optimal exercise threshold of the irreversible harvesting opportunity and thereby prolongs the optimal rotation period. Numerical illustration indicates that the optimal threshold becomes higher at an increasing rate.
\end{abstract}

JEL Code: Q23, G31, C61.

Keywords: forest rotation, optimal stopping, stochastic interest rates.

Luis H. R. Alvarez

Department of Economics

Quantitative Methods in Management

Turku School of Economics and Business

Administration

FIN-20500 Turku

Finland

luis.alvarez@tukkk.fi

\author{
Erkki Koskela \\ Department of Economics \\ University of Helsinki \\ FIN-00014 University of Helsinki \\ Finland \\ erkki.koskela@helsinki.fi
}

The research of Luis H. R. Alvarez has been supported by the Foundation for the Promotion of the Actuarial Profession and the Yrjö Jahnsson Foundation. Erkki Koskela thanks the Research Unit of Economic Structures and Growth (RUESG) in the University of Helsinki and the Yrjö Jahnsson Foundation for financial support. 


\section{Introduction}

In forest economics the Faustmannian framework has been the most often used starting point in the analyses of optimal rotation period of forest stands. Under the assumption of constant timber price, constant total cost of clear-cutting and replanting as well as constant interest rate, perfect capital markets and perfect foresight the basic model leads to a constant rotation period for an even age stand, which maximizes the present value of forest stand over an infinite time horizon (see e.g. Samuelson 1976). The representative rotation age depends on timber price, total cost of clear-cutting and replanting, nature of forest growth as well as the interest rate. The perfect foresight assumption has been relaxed in studies focusing on the implications of stochastic timber prices (see e.g. Insley 2002), risk of forest fire (see e.g. Reed 1984) and stochastic forest growth on optimal rotation age (see e.g. Clarke and Reed 1989,1990, and Willassen 1998 and Alvarez 2001b). In the case of forest fire risk modelled as a Poisson process the rotation age will become shorter due to the higher effective discount rate, while under timber price and forest growth risk usually the reverse happens; higher risk will tend to lengthen the rotation period.

To our knowledge all the research has, however, used the assumption of constant interest rate, which is problematic because forest rotation periods are long and interest rates fluctuate over time. In this paper we analyze an important, but unexplored, issue of the impact of variable and stochastic interest rate on optimal forest rotation when forest value is also stochastic by using a Wicksellian framework of a single rotation. We model the stochastic interest rate as a parametrized mean reverting process (the so-called Cox-Ingersoll-Ross model of the interest rate) and the forest value as a simpler form of geometric Brownian motion and provide an explicit solution for two-dimensional path-dependent optimal stopping problem. We show that higher interest rate volatility increases the optimal exercise threshold of the harvesting opportunity and therefore prolongs the optimal rotation period. Numerical illustration indicates that the optimal threshold becomes higher at an increasing rate.

We proceed as follows: Section 2 presents a solvable model for optimal forest rotation 
in the presence of interest rate and forest value uncertainties and finally there is a brief conclusion.

\section{Optimal Forest Rotation: A Solvable Model}

Consider the following (path-dependent) Wicksellian optimal rotation problem

$$
V(x, r)=\sup _{\tau} \mathbf{E}_{(x, r)}\left[e^{-\int_{0}^{\tau} r_{s} d s} X_{\tau}\right],
$$

where the underlying forest value and interest rate processes $\left(X_{t}, r_{t}\right)$ evolve according to the dynamics described by the following stochastic differential equations

$$
d r_{t}=\left(a-b r_{t}\right) d t+c \sqrt{r_{t}} d W_{t}, \quad r_{0}=r
$$

and

$$
d X_{t}=\mu X_{t} d t+\sigma X_{t} d \hat{W}_{t}, \quad X_{0}=x
$$

where $a, b, c, \sigma, \mu \in \mathbb{R}_{+}$are known exogenously given constants and $W_{t}$ and $\hat{W}_{t}$ are two stochastically independent Wiener processes (under the objective probability measure $\mathbb{P})$. According to $(2.2)$ the interest rate follows a mean reverting process and according to (2.3) the forest value follows a geometric Brownian motion. It is worth emphasizing that the interest rate model (2.2) is known in financial economics as the Cox-Ingersoll-Rossmodel of the interest rate which can be supported theoretically and lies in conformity with empirics (cf. Björk 1998, chapter 17, and Cochrane 2001, chapters 19, 20).

Having characterized the underlying stochastic dynamics in (2.2) and (2.3) and the corresponding optimal single rotation problem (2.1) we can now state the following

Lemma 2.1. The path-dependent optimal rotation problem (2.1) can be re-expressed as an ordinary path-independent optimal stopping problem

$$
V(x, r)=x e^{A r} \sup _{\tau} \mathbf{E}_{r}\left[e^{(\mu+a A) \tau-A \hat{r}_{\tau}}\right],
$$

where

$$
A=\frac{b}{c^{2}}-\sqrt{\frac{b^{2}}{c^{4}}+\frac{2}{c^{2}}}<0
$$


denotes the negative root of the quadratic equation $c^{2} z^{2}-2 b z-2=0$ and

$$
d \hat{r}_{t}=\left(a-\left(b-A c^{2}\right) \hat{r}_{t}\right) d t+c \sqrt{\hat{r}_{t}} d W_{t}, \quad \hat{r}_{0}=r .
$$

Proof. See Appendix A.

Lemma 2.1 is important in the sense that under the assumptions we have made concerning the stochastic processes modelling the interest rate and the forest value, the path-dependent single rotation problem can actually be transformed into an ordinary path-independent optimal stopping problem. Our main new result is now summarized in the following

Theorem 2.2. Assume that the absence of speculative bubbles condition $\mu+a A<0$ is satisfied. Then the value of the single rotation problem (2.1) reads as

$$
V(x, r)=x e^{A r} \psi(r) \sup _{y \geq r}\left[\frac{e^{-A y}}{\psi(y)}\right]= \begin{cases}x, & r \geq r^{*} \\ x e^{A\left(r-r^{*}\right)} \frac{\psi(r)}{\psi\left(r^{*}\right)}, & r<r^{*}\end{cases}
$$

where the increasing fundamental solution

$$
\psi(r)=\int_{0}^{1} e^{2\left(b-A c^{2}\right) r t / c^{2}} t^{\rho-1}(1-t)^{2 a / c^{2}-\rho-1} d t
$$

is known as Kummer's confluent hypergeometric function (see e.g. Abramowitz and Stegun 1968, pp. 503-535) and

$$
\rho=\frac{\mu+a A}{A c^{2}-b}>0
$$

Moreover, the optimal exercise threshold $r^{*}$ is the unique root of the ordinary first order condition $\psi^{\prime}\left(r^{*}\right)=-A \psi\left(r^{*}\right)$. Especially, $r^{*}>\mu$ for all $c>0$ and $r^{*}=\mu$ when $c=0$.

Proof. See Appendix B.

Theorem 2.2 demonstrates that the path-dependent optimal rotation problem (2.4) is explicitly solvable whenever the absence of speculative bubbles condition $a A+\mu<0$ is satisfied. It is worth observing that since

$$
\frac{\partial A}{\partial c}=\frac{c A^{2}}{b-c^{2} A}>0
$$


and $A \downarrow-1 / b$ as $c \downarrow 0$ we find that the absence of speculative bubbles condition can be satisfied only if the inequality $\mu<a / b$, stating that the expected percentage growth rate of the revenues has to be smaller than the long run steady state interest rate, holds. If this is indeed the case, then there is a critical volatility $c^{*}$, satisfying the condition

$$
\mu c^{* 2}=a b-\sqrt{a^{2} b^{2}+2 a^{2} c^{* 2}}
$$

above which the the absence of speculative bubbles condition $a A+\mu<0$ is violated and, therefore, above which the value of the optimal policy becomes unbounded. We find that the condition $\mu+a A<0$ is strengthened by the higher volatility described by the parameter $c$. This increases the required exercise premium and, thus, prolongs the optimal rotation period.

In Figure 1 we illustrate the optimal rotation threshold under the assumption that $b=0.1, a=0.045 b$, and $\mu=0.03$ (implying that the critical volatility above which the absence of speculative bubbles condition $a A+\mu<0$ is violated is $c^{*}=12.25 \%$ ). As

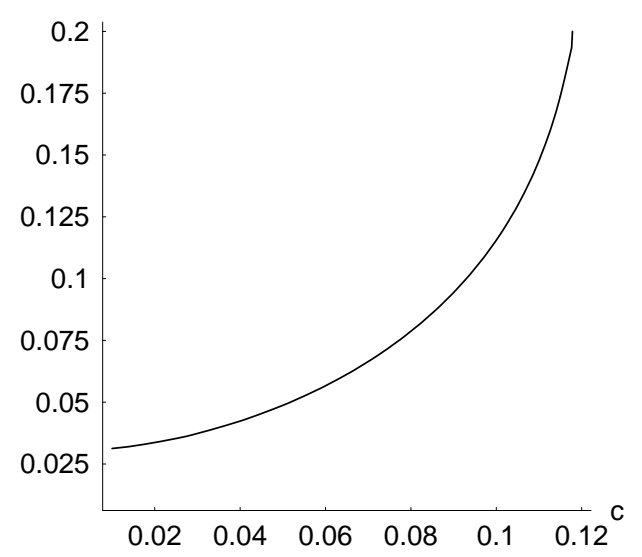

Figure 1: The optimal rotation threshold as a function of $c$

one can immediately observe from Figure 1, increased volatility not only increases the optimal threshold, but does it at an increasing rate. Thus, close to the critical levels where the absence of speculative bubbles condition is compromised, a small increase in the volatility coefficient results into a relatively large increase in the required exercise 
premium so that the optimal rotation period will increase more than the volatility.

\section{Conclusions}

To our knowledge all the research about the determination of optimal forest rotations has used the assumption of constant interest rate, which is problematic because forest rotation periods are long and interest rates fluctuate over time. In this paper we have used the Wicksellian single rotation framework to study an unexplored issue of forest rotation under variable and stochastic interest rate when forest value is also stochastic. We have modelled the stochastic interest rate as a parametrized mean reverting process by using the Cox-Ingersoll-Ross model of interest rate - which is well-known in financial economics, can be supported theoretically and lies in conformity with empirics - and the forest value as a simpler form of geometric Brownian motion. We have provided an explicit solution for two-dimensional path-dependent optimal stopping problem and shown that higher interest rate volatility increases the optimal threshold and therefore prolongs the optimal rotation period. Numerical illustration indicates that the optimal threshold is a strictly convex function of the volatility coefficient of the underlying interest rate process. Thus our illustrations indicate that the optimal exercise threshold becomes higher at an increasing rate as the interest rate volatility increases.

Whether our conclusions remain valid in the Faustmann's ongoing rotation framework is an open question beyond the scope of this paper. Given the close connection of impulse control problems and optimal stopping theory (see Alvarez 2001b) we are tempted to conjecture that our conclusions will likely remain qualitatively valid in the Faustmann framework as well. But the verification of this conjecture is an open issue for further research.

Acknowledgements: The research of Luis H. R. Alvarez has been supported by the Foundation for the Promotion of the Actuarial Profession and the Yrjö Jahnsson Foundation. Erkki Koskela thanks the Research Unit of Economic Structures and Growth 
(RUESG) in the University of Helsinki and the Yrjö Jahnsson Foundation for financial support.

\section{References}

[1] Abramowitz, M. and Stegun, I. A., eds., Handbook of mathematical functions, 1968, Dover Publications, New York.

[2] Alvarez, L. H. R. Reward functionals, salvage values, and optimal stopping, 2001a, Mathematical Methods of Operations Research, 54, 315-337.

[3] Alvarez, L. H. R. Stochastic Forest Growth and Faustmann's Formula, 2001b, Turku School of Economics and Business Administration, mimeo.

[4] Björk, T. Arbitrage Theory In Continuous Time, 1998, Oxford UP, Somerset.

[5] Clarke, H. R. and Reed, W. J. The tree-cutting problem in a stochastic environment, 1989, Journal of Economic Dynamics and Control, 13, 569-595.

[6] Clarke, H.R. and Reed, W.J Harvest decisions and asset valuations for biological resources exhibiting size-dependent stochastic growth, 1990, International Economic Review, 31, 147-169.

[7] Cochrane, J.H. Asset Pricing, 2001, Princeton University Press.

[8] Insley, M. A real options approach to the valuation of a forestry investment, 2002, Journal of Environmental Economics and Management, 44, 471-492.

[9] Øksendal, B. Stochastic differential equations: An introduction with applications, (Fifth Edition) 1998, Springer, Berlin.

[10] Reed, W. J. The effects of the risk of fire on the optimal rotation of a forest, 1984, Journal of Environmental Economics and Management, 11, 180-190.

[11] Samuelson, P. A. Economics of forestry in an evolving society, 1976, Economic Inquiry, 14, 466-492. 
[12] Willassen, Y. The stochastic rotation problem: A generalization of Faustmann's formula to stochastic forest growth, 1998, Journal of Economic Dynamics and Control, 22, 573-596.

\section{A Proof of Lemma 2.1}

Since

$$
X_{t}=x \exp \left(\left(\mu-\sigma^{2} / 2\right) t+\sigma \hat{W}_{t}\right)
$$

we find by applying Itô's theorem to the mapping $r \mapsto e^{z r}$ that

$$
e^{-\frac{1}{2}\left(z^{2} c^{2}-2 z b\right) \int_{0}^{t} r_{s} d s}=e^{z\left(r-r_{t}\right)+z a t} M_{t}
$$

where

$$
M_{t}=\exp \left(\int_{0}^{t} z c \sqrt{r_{s}} d W_{s}-\frac{1}{2} \int_{0}^{t} z^{2} c^{2} r_{s} d s\right)
$$

is a positive exponential martingale. Thus, choosing $z=A$ implies that the discount factor can be re-expressed as

$$
e^{-\int_{0}^{t} r_{s} d s}=e^{A\left(r-r_{t}\right)+A a t} M_{t}
$$

Therefore, we find that the present value of the forest stand can be expressed as

$$
e^{-\int_{0}^{t} r_{s} d s} X_{t}=x e^{A\left(r-r_{t}\right)+A a t+\mu t} \hat{M}_{t} M_{t}
$$

where $\hat{M}_{t}=e^{\sigma \hat{W}_{t}-\frac{1}{2} \sigma^{2} t}$ is a positive exponential martingale. Consequently, we find that the path-dependent optimal rotation problem (2.1) can be re-expressed as an ordinary path-independent optimal stopping problem

$$
V(x, r)=x e^{A r} \sup _{\tau} \mathbf{E}_{r}\left[e^{(\mu+a A) \tau-A r_{\tau}} \hat{M}_{\tau} M_{\tau}\right] .
$$

Defining the equivalent measure $\mathbb{Q}$ through the likelihood-ratio $\frac{d \mathbb{Q}}{d \mathbb{P}}=\hat{M}_{t} M_{t}$ we can now re-express (A.1) as

$$
V(x, r)=x e^{A r} \sup _{\tau} \mathbf{E}_{r}^{\mathbb{Q}}\left[e^{(\mu+a A) \tau-A r_{\tau}}\right]
$$


where the interest rate process $r_{t}$ evolves under $\mathbb{Q}$ according to the dynamics described by the stochastic differential equation

$$
d r_{t}=\left(a-\left(b-A c^{2}\right) r_{t}\right) d t+c \sqrt{r_{t}} d \tilde{W}_{t}, \quad r_{0}=r,
$$

where $\tilde{W}_{t}$ is a standard Brownian motion under the equivalent measure $\mathbb{Q}$. However, given the strong uniqueness of a solution for the stochastic differential equation above (cf. Øksendal, 1998, p. 66) we finally find that the rotation problem (2.1) can be rewritten in the path-independent form (2.4) defined under the objective measure $\mathbb{P}$.

\section{B Proof of Theorem 2.2}

Proof. Since

$$
L(r)=\mathbf{E}_{r}\left[e^{(\mu+a A) \tau-A \hat{r}_{\tau}}\right]
$$

is an ordinary path-independent optimal stopping problem of a linear diffusion and, therefore, can be solved by relying on ordinary variational inequalities, the alleged result is a direct implication of Theorem 3 in Alvarez 2001 a. It is, therefore, sufficient to determine the increasing fundamental solution of the ordinary second order differential equation

$$
\frac{1}{2} c^{2} r u^{\prime \prime}(r)+\left(a-\left(b-c^{2} A\right) r\right) u^{\prime}(r)+(\mu+a A) u(r)=0 .
$$

Making the transformation $u(r)=v(\theta r)$, where $\theta \in \mathbb{R}$ is an unknown constant, and defining the variable $y=\theta r$ then yields that

$$
y v^{\prime \prime}(y)+\left(\frac{2 a}{c^{2}}-\frac{2\left(b-A c^{2}\right)}{c^{2} \theta} y\right) v^{\prime}(y)+\frac{2(\mu+a A)}{\theta c^{2}} v(y)=0 .
$$

Choosing $\theta=2\left(b-A c^{2}\right) / c^{2}$, then finally implies that the differential equation can equivalently be expressed as

$$
y v^{\prime \prime}(y)+\left(\frac{2 a}{c^{2}}-y\right) v^{\prime}(y)-\frac{2(\mu+a A)}{A c^{2}-b} v(y)=0,
$$

which is Kummer's differential equation. 


\title{
CESifo Working Paper Series
}

\author{
(for full list see www.cesifo.de)
}

805 Friedrich Breyer and Stefan Felder, The Dead-anyway Effect Revis(it)ed, October 2002

806 Assar Lindbeck and Solveig Wikström, E-exchange and the Boundary between Households and Organizations, November 2002

807 Dieter Bös, Contests Among Bureaucrats, November 2002

808 Steven Brakman, Harry Garretsen, and Marc Schramm, The Strategic Bombing of German Cities during World War II and its Impact on City Growth, November 2002

809 Florian Englmaier and Achim Wambach, Contracts and Inequity Aversion, November 2002

810 Sarbajit Sengupta, Delegating Recruitment under Asymmetric Information, December 2002

811 Rajshri Jayaraman, On the Partial Public Provision of a Private Good, December 2002

812 Stéphanie Stolz, Banking Supervision in Integrated Financial Markets: Implications for the EU, December 2002

813 Christian Keuschnigg, Taxation of a Venture Capitalist with a Portfolio of Firms, December 2002

814 Inés Macho-Stadler and David Pérez-Castrillo, Settlement in Tax Evasion Prosecution, December 2002

815 Rainer Niemann and Dirk Simons, Costs, Benefits, and Tax-induced Distortions of Stock Option Plans, December 2002

816 Jan-Egbert Sturm and Barry Williams, Deregulation, Entry of Foreign Banks and Bank Efficiency in Australia, December 2002

817 V. Anton Muscatelli, Patrizio Tirelli, and Carmine Trecroci, Monetary and Fiscal Policy Interactions over the Cycle: Some Empirical Evidence, December 2002

818 Claude Hillinger, A General Theory of Price and Quantity Aggregation and Welfare Measurement, December 2002

819 Erkki Koskela and Ronnie Schöb, Optimal Capital Taxation in Economies with Unionised and Competitive Labour Markets, December 2002

820 Sheilagh Ogilvie, Guilds, Efficiency, and Social Capital: Evidence from German ProtoIndustry, December 2002 
821 Hans Gersbach and Verena Liessem, Financing Democracy, December 2002

822 Costas Hadjiyiannis, Panos Hatzipanayotou, and Michael S. Michael, Optimal Tax Policies with Private-Public Clean-Up, Cross-Border Pollution and Capital Mobility, December 2002

823 François Ortalo-Magné and Sven Rady, Homeownership: Low Household Mobility, Volatile Housing Prices, High Income Dispersion, December 2002

824 Syed M. Ahsan and Panagiotis Tsigaris, Measuring the Social Discount Rate under Uncertainty: A Methodology and Application, December 2002

825 Kai A. Konrad, Altruism and Envy in Contests: An Evolutionarily Stable Symbiosis, December 2002

826 Robert S. Chirinko and Huntley Schaller, A Revealed Preference Approach to Understanding Corporate Governance Problems: Evidence from Canada, December 2002

827 Geir B. Asheim, Green National Accounting for Welfare and Sustainability: A Taxonomy of Assumptions and Results, December 2002

828 Andrea Gebauer, Chang Woon Nam, and Rüdiger Parsche, Lessons of the 1999 Abolition of Intra-EU Duty Free Sales for Eastern European EU Candidates, December 2002

829 Giacomo Corneo, Work and Television, December 2002

830 Vivek H. Dehejia and Yiagadeesen Samy, Trade and Labour Standards - Theory, New Empirical Evidence, and Policy Implications, December 2002

831 Geir B. Asheim and Wolfgang Buchholz, A General Approach to Welfare Measurement through National Income Accounting, December 2002

832 Aaron Tornell and Frank Westermann, The Credit Channel in Middle Income Countries, January 2003

833 Gebhard Flaig, Time Series Properties of the German Monthly Production Index, January 2003

834 Campbell Leith and Jim Malley, Estimated Open Economy New Keynesian Phillips Curves for the G7, January 2003

835 Burkhard Heer and Bernd Süssmuth, Inflation and Wealth Distribution, January 2003

836 Erkki Koskela and Leopold von Thadden, Optimal Factor Taxation under Wage Bargaining - A Dynamic Perspective, January 2003

837 Carola Grün and Stephan Klasen, Growth, Income Distribution, and Well-Being: Comparisons across Space and Time, January 2003 
838 Robert S. Chirinko and Ulf von Kalckreuth, On the German Monetary Transmission Mechanism: Interest Rate and Credit Channels for Investment Spending, January 2003

839 Sascha O. Becker, Andrea Ichino, and Giovanni Peri, How Large is the "Brain Drain" from Italy?", January 2003

840 Albert Berry and John Serieux, All About the Giants: Probing the Influences on Growth and Income Inequality at the End of the $20^{\text {th }}$ Century, January 2003

841 Robert Fenge and Martin Werding, Ageing and the Tax Implied in Public Pension Schemes: Simulations for Selected OECD Countries, January 2003

842 Robert Fenge and Martin Werding, Ageing and Fiscal Imbalances Across Generations: Concepts of Measurement, January 2003

843 Giovanni Andrea Cornia, The Impact of Liberalisation and Globalisation on Income Inequality in Developing and Transitional Economies, January 2003

844 Peter Fredriksson and Per Johansson, Program Evaluation and Random Program Starts, January 2003

845 Bernd Hayo and Matthias Wrede, Fiscal Equalisation: Principles and an Application to the European Union, January 2003

846 Syed M. Ahsan and Jaideep Oberoi, Inequality, Well-being and Institutions in Latin America and the Caribbean, January 2003

847 Chang Woon Nam and Doina Maria Radulescu, The Role of Tax Depreciation for Investment Decisions: A Comparison of European Transition Countries, January 2003

848 V. Bhaskar and Steinar Holden, Wage Differentiation via Subsidised General Training, January 2003

849 Paloma Lopez-Garcia, Labour Market Performance and Start-up Costs: OECD Evidence, January 2003

850 Christian Keuschnigg and Soren Bo Nielsen, Public Policy for Start-up Entrepreneurship with Venture Capital and Bank Finance, January 2003

851 Yin-Wong Cheung, Menzie D. Chinn, and Eiji Fujii, China, Hong Kong, and Taiwan: A Quantitative Assessment of Real and Financial Integration, January 2003

852 Gregory D. Hess, The Economic Welfare Cost of Conflict: An Empirical Assessment, February 2003

853 Douglas J. Cumming and Jeffrey G. MacIntosh, Comparative Venture Capital Governance. Private versus Labour Sponsored Venture Capital Funds, February 2003

854 Eckhard Janeba and John Douglas Wilson, Decentralization and International Tax Competition, February 2003 
855 Tapio Palokangas, Capital Accumulation and Employment Cycles in a Model of Creative Destruction, February 2003

856 Brendan Walsh, When Unemployment Disappears: Ireland in the 1990s, February 2003

857 Luis H. R. Alvarez and Erkki Koskela, A General Approach to the Stochastic Rotation Problem with Amenity Valuation, February 2003

858 Christian Schultz, Strategic Campaigns and Redistributive Politics, February 2003

859 Ernst Fehr and Joseph Henrich, Is Strong Reciprocity a Maladaptation? On the Evolutionary Foundations of Human Altruism, February 2003

860 Haizhou Huang, Dalia Marin, and Chenggang Xu, Financial Crisis, Economic Recovery and Banking Development in Former Soviet Union Economies, February 2003

861 Pedro Cardoso and Bernard M.S. van Praag, How Sustainable Are Old-age Pensions in a Shrinking Population with Endogenous Labour Supply?, February 2003

862 Volker Meier, Efficient Transfer of Aging Provisions in Private Health Insurance, February 2003

863 Edward Castronova, Theory of the Avatar, February 2003

864 Robert S. Chirinko, Hans van Ees, Harry Garretsen, and Elmer Sterken, Investor Protections and Concentrated Ownership: Assessing Corporate Control Mechanisms in the Netherlands, February 2003

865 Bernard M.S. van Praag and Pedro Cardoso, The Mix Between Pay-as-you-go and Funded Pensions and what Demography has to do with it, February 2003

866 Ernst Fehr, Urs Fischbacher, Bernhard von Rosenbladt, Jürgen Schupp, and Gert G. Wagner, A Nation-Wide Laboratory. Examining Trust and Trustworthiness by Integrating Behavioral Experiments into Representative Survey, February 2003

867 Frank Heinemann, The Inflationary Impact of Wage Indexation, February 2003

868 Eytan Sheshinski, Bounded Rationality and Socially Optimal Limits on Choice in a Self-Selection Model, February 2003

869 M. Hashem Pesaran, Estimation and Inference in Large Heterogenous Panels with Cross Section Dependence, February 2003

870 Luis H. R. Alvarez and Erkki Koskela, On the Tree-Cutting Problem under Interest Rate and Forest Value Uncertainty, February 2003 